\title{
Preparation, morphology, FTIR and performance properties of foaming particleboard
}

\author{
Xiaoyu Bi and Runzhou Huang ${ }^{*}$ (i)
}

\begin{abstract}
The application of light weight particleboard in furniture industry becomes more inevitable because of the requirement to facilitate transportation and assembly by the customer. Herein, a novel method for the fabrication of foaming particleboard was proposed, which is achieved by adding azodicarbonamide (AC) foaming agent into the formulation that consist of oven-dry poplar (Populus alba) particles (with the moisture content about 4\%) and phenol formaldehyde resin (PF resin) (solid content of 48\%). In this study, the effects of AC foaming agent and adhesive contents incorporation and its content on mechanical, physical and chemical properties of particleboards were investigated. The results showed that the addition of AC foaming agent played a critical role in properties of particleboard and the optimal particleboard performance was achieved at the particleboard density of $0.6 \mathrm{~g} / \mathrm{cm}^{3}$, the PF resin amount of $12 \%$, and the AC foaming agent amount of $1 \%$. Furthermore, the pores appeared on the particle surface were the products of the radical pyrolysis of the foaming agent, which has been proved by the FTIR results and the pores also affect the properties of the particleboards.
\end{abstract}

Keywords: Particleboard, AC foaming agent, Adhesive content, Pore structure

\section{Introduction}

Low-density particleboard (PB) is a particleboard with a density of $0.25-0.4 \mathrm{~g} / \mathrm{cm}^{3}$, light and soft texture, relatively good strength, water resistant and dimensional stability. Due to its fluffy interior, low-density particleboard has ideal performance of sound insulation, heat preservation and mechanical processing, which makes it an excellent material for furniture, architecture and interior decoration [1, 2]. Some scholars in Japan have investigated the low-density particleboard for a long time, they use Cryptomeria fortunei as the raw material while isocyanic vinegar as the adhesive to press and prepare the low-density particleboard, and formulate the JISA5908 Low-Density Particleboard Standard [3-6]. The traditional foaming

\footnotetext{
*Correspondence: runzhouhuang@njfu.edu.cn

Co-Innovation Center of Efficient Processing and Utilization of Forest Products, College of Materials Science and Engineering, Nanjing Forestry University, Nanjing 210037, China
}

particleboard is defined as a sandwich structure panel consisting of a foaming liquid core and particleboard facings [7]. The customer's demand for lightweight panel furniture is the fundamental driving force for the development of foamed particleboard, and the foam core layer can also provide good thermal insulation performance. However, the use of foam materials in the core layer will definitely cause a certain degree of loss of mechanical properties, making the plate unable to be used in loadbearing structures. Azodicarbonamide (AC) foaming agent is widely used because of its high gas output $(>200$ $\mathrm{ML} / \mathrm{g}$ ), stable performance, non-flammable, continuous and uniform foaming under normal pressure and pressure, without affecting the curing of the adhesive. And it was the fundamental factors why the AC foaming agent was chosen as raw materials. Wang and Sun from the Institute of Biological and Agricultural Engineering of the University of Kansas utilized cornstalk and wheat straw to prepare the low-density particleboards and
Springer Open
C The Author(s) 2021. Open Access This article is licensed under a Creative Commons Attribution 4.0 International License, which permits use, sharing, adaptation, distribution and reproduction in any medium or format, as long as you give appropriate credit to the original author(s) and the source, provide a link to the Creative Commons licence, and indicate if changes were made. The images or other third party material in this article are included in the article's Creative Commons licence, unless indicated otherwise in a credit line to the material. If material is not included in the article's Creative Commons licence and your intended use is not permitted by statutory regulation or exceeds the permitted use, you will need to obtain permission directly from the copyright holder. To view a copy of this licence, visit http://creativecommons.org/licenses/by/4.0/. 
analyzed the impacts of board density designed when pressing the board, straw dimension, hot pressing time, and the soybean glue used on the board comprehensive strength and tensile strength. The results showed that the density increased from 0.3 to $0.34 \mathrm{~g} / \mathrm{cm}^{3}$, and the tensile strength and compressive strength increased from 2.11 and 3.02 MPa to 3.24 and 4.29 MPa, respectively [8].

At the beginning of the twenty-first century, the Fujian Institute of Forestry united the Nanping continent woodyard man-made board factory to produce the low-density particleboard with a breadth of $1220 \times 2440 \mathrm{~mm}$, a thickness of $35-42 \mathrm{~mm}$, and density of $0.4 \mathrm{~g} / \mathrm{cm}^{3}$. And the raw material was the light cedarwood with low density and small caliber [9-11]. To better exploit and utilize the low-density cement-bonded particleboard, Yu carried out in-depth research based on the wood science and technology discipline and related discipline theoretical knowledge, systemically investigated the low-density cement-bonded particleboard using the modern instruments (such as thermal analyzer, X-ray diffractometer, Fourier Infrared Spectrometer, and cone calorimeter). The author discovered the change characteristics of the bonding strength between wood and cement, the hydration temperatures of multiple wood-cement mixtures and their changing process, and the hydration mechanism of wood materials to cement. The series research results have provided evidence for selecting the producing wood materials for cement-bonded particleboard and improving the compatibility between wood and cement [12]. Zhao et al. employed the phenolic resin adhesive foaming mechanism to produce the low-density particleboard and discovered that the pressure produced during the foaming of adhesive rendered more sufficient contact between the wood particles and adhesive, thus obtaining the more superb bond strength. In the meantime, the massive micropore structures inside the board also reduced the board weight, and the product produced through such a pressing method had a minimum density of $0.4 \mathrm{~g} / \mathrm{cm}^{3}$ [13]. Jiang et al. prepared the core material with poplar particles and expanded polystyrene (EPS) as the raw materials. Besides, its surface was covered with Populus veneer to prepare the wood composite board to enhance the board mechanical property. The results suggested that the board internal bonding strength and static bending strength reached the national standard requirements of class A particleboard second when the composite board density was $0.42-0.48 \mathrm{~g} / \mathrm{cm}^{3}$, and the heat conductivity was lower than $0.050 \mathrm{~W} /(\mathrm{m} \mathrm{K})$, which might be used as the non-stressed part and wall heatinsulating material in furniture and interior decoration $[14,15]$. Han utilized polyvinyl chloride plastics (PVC), wood powders, and $\mathrm{AC}$ foaming agents as the raw materials to prepare the PVC-based wood-plastic composite crust foaming floor base material by the extrusion molding method. The foamed wood powder composite material had a favorable foam structure, which resulted in crack crest truncation and effectively prevented crack extension, thus greatly improving the material ductility and impact resistance and significantly reducing the product density. Besides, the various product physical performance indexes met relevant requirements, which was suitable for scale production in factories [16-18]. Chen analyzed the influences of process parameters during the polyethylene (PE)-based wood-plastic composite material processing on the material property. Specifically, they focused on investigating the impacts of AC foaming agent content, toughening material content (nanoscale particles, wood powders), and nucleating agent content on the composite material density and toughness, and determined the favorable process parameters for polymer processing, so that it was of great promotion value [19]. Wang prepared the foaming flame retarding wood-plastic composite material through the hot pressing molding process, using the major raw materials of high-density polyethylene (HDPE) and rice hulls, with the addition of foaming agent and addition agent, and some composite materials were added with single flame retardant. The mechanical property and physical properties (such as water absorption capacity and heat-conducting property) were tested to analyze the influences of different types of foaming agents, flame retardants contents, and base proportions on the composite material performance [20]. Nadhari et al. pre-treated the dried banana trunk wastes particles with different chosen temperatures steam before fabricate the binderless particleboard. There were a dramatically decrease on the ratio of thickness swelling and water absorption properties, which led to a subsequence that the dimensional stability improved apparently. It is considered that steam pre-treatment hydrolyzes cellulose and hemicellulose partially so that declining further moisture sorption and enhances the fiber compressibility, which lower the internal pressure emerged at the hot pressing stage, it also improve the thickness swelling [21]. Iswanto et al. immersed particle in various level acetic acid (AA) solution for $24 \mathrm{~h}$ before hot pressing procedure, which led to a moderate improvement on the dimensional property. It also results that the excess of $1 \%$ AA level could cause negative effects on mechanical properties including modulus of rupture (MOR), modulus of elasticity (MOE) and internal bonding strength (IB) [22]. Widyorini et al. used citric acid as natural binder in the fabricating of bamboo particleboard, which offered a distinguished performance on dimensional stability and mechanical properties [23].

This study was carried out aiming to investigate a set of complete production techniques (including hot pressing 
temperature, time, pressure, as well as the optimal proportions of wood particle, adhesive and AC foaming agent), effectively combine $\mathrm{AC}$ foaming agent with traditional particleboard, prepare the low-density particleboard, and endow it with favorable strength-to-weight ratio, dimensional stability, and heat insulation property, which allowed to intensify the usability of the existing man-made board, expand the product application range, and produce superb products for the application in actual production. Therefore, this program used a foaming agent to treat the particles directly for microcellular foaming, and aimed to produce a new type of foamed particle board that can ensure that the mechanical properties will not be significantly reduced. It also hoped to possess a low water absorption and high thermal insulation properties to sustain the superiority of products. To be specific, this study realizes the reinforcement of traditional particleboard, improves the usability and processability of the commonly used ordinary particleboard, oriented strand board, and bamboo particleboard, and expands the application range of particleboard. Moreover, it compensates for defects of traditional man-made board, such as poor physical and mechanical properties and substantially declined dimensional stability due to the high water absorption.

\section{Materials and methods Raw materials}

The poplar particles were obtained from the Populus Experimental Forest of Nanjing Forestry University and the particles were dried at a temperature of $103{ }^{\circ} \mathrm{C}$ to reduce the moisture content of the wood particles to less than $4 \%$ in a laboratory before manufacturing. And the particles were classified using a vibrating machine and sieves of 6 mesh $(3.20 \mathrm{~mm}), 10$ mesh $(2.00 \mathrm{~mm}), 20$ mesh $(0.85 \mathrm{~mm}), 40$ mesh $(0.45 \mathrm{~mm})$, the proportions of the five sizes of particles are as follows, $>3.2 \mathrm{~mm}(23 \%), 2.0$ $3.2 \mathrm{~mm}$ (22\%), 0.9-2.0 mm (39\%), 0.45-0.9 mm (11\%) less than $0.45 \mathrm{~mm}$ (5\%). Phenolic resin adhesive with 48 wt $\%$ solid content was purchased from Dynea Chemical Co (Helsinki, Finland), and AC foaming agent was purchased from Jiyesheng Chemical Co (Wuhan, China). The formulation of PB is given in Table 1

\section{Preparation and characterization of foaming particleboard Preparation of foaming particleboard}

The oven-dry particles, phenolic resin adhesive (solid content, 48\%) and AC foaming agent were weighed, respectively, by using the electronic scales (MettlerToledo, Giessen, Germany). Then the AC foaming agent was diluted with distilled water to 20-fold before use. Oven dry Populus wood particles, phenolic resin adhesive, and AC foaming agent were added in succession
Table 1 Formulation of PB

\begin{tabular}{llll}
\hline Type & $\begin{array}{l}\text { PF (\%) (solid content } \\
\mathbf{4 8 \%}\end{array}$ & $\mathbf{A C}(\%)$ & $\begin{array}{l}\text { Target } \\
\text { density (g/ } \\
\mathbf{c m}^{\mathbf{3}} \text { ) }\end{array}$ \\
\hline 1 & 10 & 1.2 & 0.3 \\
2 & 10 & 1.2 & 0.4 \\
3 & 10 & 1.2 & 0.5 \\
4 & 10 & 0 & 0.5 \\
5 & 6 & 1 & 0.6 \\
6 & 8 & 1 & 0.6 \\
7 & 10 & 1 & 0.6 \\
8 & 12 & 1 & 0.6 \\
9 & 6 & 1.2 & 0.6 \\
10 & 8 & 1.2 & 0.6 \\
11 & 10 & 1.2 & 0.6 \\
12 & 12 & 1.2 & 0.6 \\
13 & 6 & 1.4 & 0.6 \\
14 & 8 & 1.4 & 0.6 \\
15 & 10 & 1.4 & 0.6 \\
16 & 12 & 1.4 & 0.6 \\
\hline
\end{tabular}

according to the proportions in Table 1 and sufficiently stirred for $15 \mathrm{~min}$ in the ring mixer (Runying Nijiala Machinery, SY, China). After sufficiently stirring, the particles were taken out timely, placed into the $30 \times 30 \mathrm{~cm}$ mold in a laboratory, pre-pressed manually so that they became slab with a certain strength and did not collapse or damage during the hot pressing process. The pre-pressed slab was placed onto the base plate covered with an oil film, the 1-cm thickness gages were placed on both sides, and then the slab was placed onto the pressing machine (Chuangjiahong Machinery Equipment, SZ, China), with the pressing machine temperature of $180{ }^{\circ} \mathrm{C}$, pressure setting of gauge pressure at $4 \mathrm{MPa}$, and the hot pressing time of $10 \mathrm{~min}$. Each of the proportions was prepared in triplicate samples. The particleboard specification was $30 \times 30 \times 1 \mathrm{~cm}$. The board was taken out after pressing the particleboard for the scheduled time, which was then cut into sizes applicable to different performance tests after cooling and were labeled.

\section{Foaming particleboard performance test}

The pressed particleboard was sawed into two $25 \times 5 \mathrm{~cm}$ test specimens, four $10 \times 10 \mathrm{~cm}$ test specimens, and four $5 \times 5 \mathrm{~cm}$ test specimens. Then, their corresponding MOR, MOE, heat conductivities, thickness swelling rates of water absorption and IB were tested, respectively.

1. The vernier caliper (MNT-150, Meinaite Co, SH, China) and electronic scales were used to measure the sizes and weights of the $5 \times 5 \mathrm{~cm}$ test specimens 
at different proportions, respectively, to calculate the actual densities of samples with different proportions. Three replicates were used for each test.

2. Samples with different proportions were placed onto the universal mechanical testing machine (CMT6104, MTS System Co., Washington, USA), the man-made board was sawed into samples which correspond to various testing conditions, and then MOR, MOE, and IB were tested according to the national standard GB/T4897-2015 [24]. This is a standard applicable to ordinary, furniture, and heavy-duty particleboards, which stipulates the definition, classification and performance testing methods of particleboard. Four replicates were used for each test.

3. The thickness swelling rate of water absorption test was conducted by the method specified in the national standard GB/T4897-2015 [24], 8 test specimens with the specification of $5 \times 5 \times 1 \mathrm{~cm}$ were prepared, among which, 4 were immersed for $24 \mathrm{~h}$, while the remaining 4 were immersed for $2 \mathrm{~h}$, separately. Then, the ratio of thickness difference before and after water absorption to the thickness before water absorption was measured. The test conditions were as follows, the samples were immersed at $5 \mathrm{~cm}$ below the water at normal temperature and pressure, and the thickness values at 5 points were measured at 2 and $24 \mathrm{~h}$, respectively, to take the average values. Four replicates were used for each test.

4. Four $10 \times 10 \mathrm{~cm}$ test specimens were collected, then, the steady-state heat conductivity measuring instrument (XMT-404/604, TRM-WD120, Sunshine Technology Co., JZ, China) was calibrated, the samples were mounted, and the sensing wires were connected to the upper and lower surfaces of the second board, respectively. The two boards on the top and bottom were covered by boards with the thermally conductive surface and clamped with foam board and hard plastic board, to guarantee stable heat transmission. After heating for $10 \mathrm{~min}$, the temperatures on the board surface were recorded. And the temperatures displayed on the channels connected to two guiding wires were recorded at 12,14,16, 18, and $20 \mathrm{~min}$, respectively. The testing steps of particleboard are shown in Fig. 1.

The test conditions were as follows, the stable heat output voltage of the heating device was $30 \mathrm{~V}$ and the current was $0.139 \mathrm{~A}$.

Based on the experiment, the particleboard heat conductivity was calculated according to the following formula after steady-state heating:

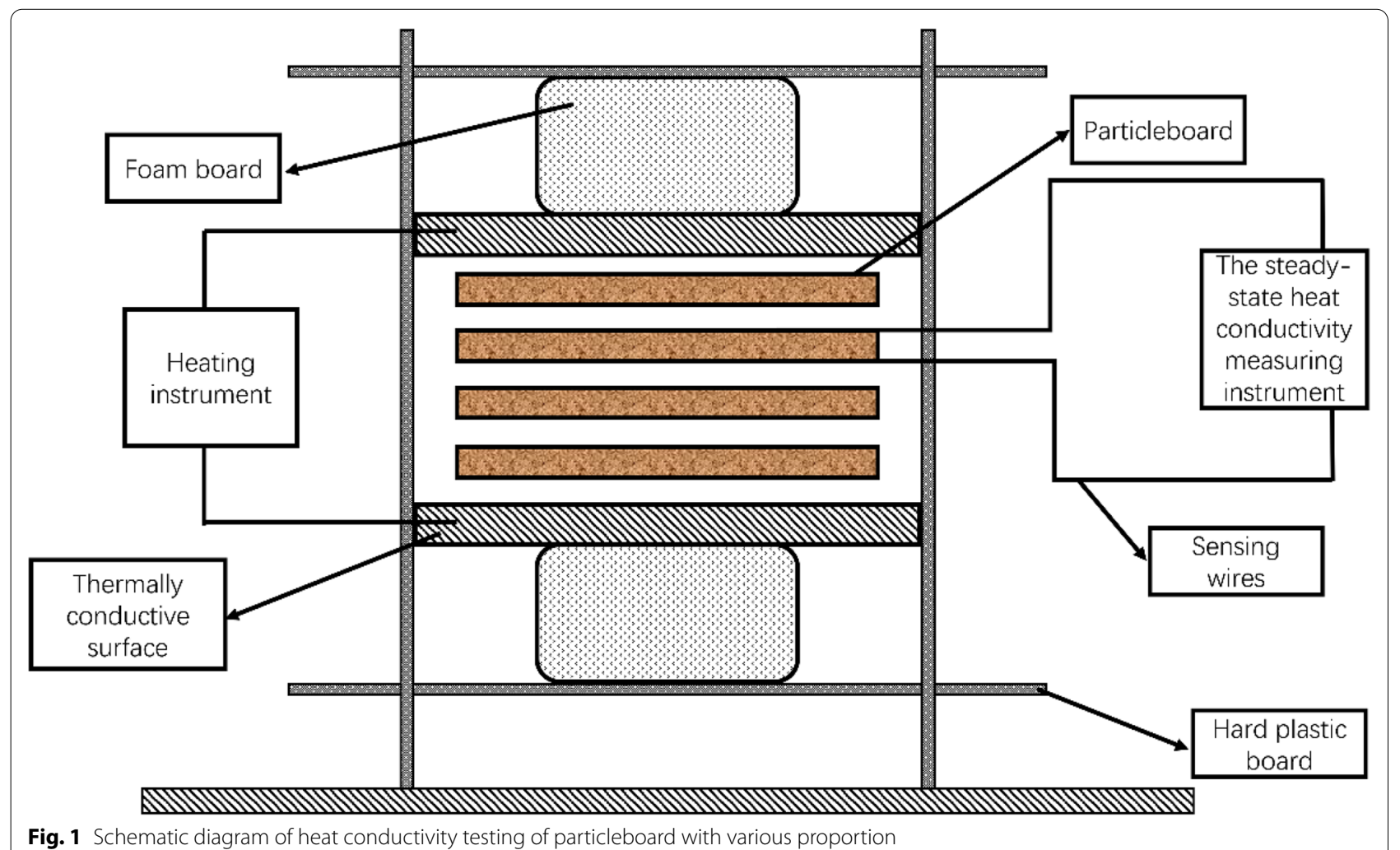

Fig. 1 Schematic diagram of heat conductivity testing of particleboard with various proportion 


$$
\lambda=\frac{q \delta}{2 \Delta t},
$$

where $\lambda$ stands for the heat conductivity (W/(m k)), $q$ indicates the heat conducted per unit area $\left(\mathrm{W} / \mathrm{m}^{2}\right), \delta$ expresses the thickness of the test samples $(\mathrm{m})$, and $\Delta t$ represents the temperature difference between two sides of the object $\left({ }^{\circ} \mathrm{C}\right)$.

$$
q=\frac{\mathrm{UI}}{F},
$$

where $U$ stands for the output voltage when the quasisteady-state conductometer is heating $(V), I$ indicates the output current when the quasi-steady-state conductometer is heating $(A)$, and $F$ is the effective area when the test sample is under heat circulation $\left(\mathrm{m}^{2}\right)$. Four replicates were used for each test.

5. The graph observed using the scanning electron microscope (SEM) was 3-dimensional, with a large depth of field, a wide adjustable-rate range, and simple sample preparation. Therefore, it is a commonly used instrument to analyze and characterize the material surface structure and morphology. Preparation of SEM samples: a small amount of the samples to be tested were evenly dispersed onto the conductive adhesive on the sample table, and the samples were subject to metal spraying for $40 \mathrm{~s}$. In this study, the S-4860 SEM (Hitachi, Japan) was adopted to characterize the material microstructure and morphology. The SEM results were an important basis that reflected the basic information like morphology of the wood unit in particleboard after foaming.

6. The Fourier transform infrared spectroscopy (FTIR) analysis was conducted on the characterization of the particleboard to determine the existence of functional groups in the hybrid particleboard units which contains the AC foaming agents. In order to obtain one spectrum, the FTIR spectrometer (VERTEX $80 \mathrm{~V}$ ) was used under the condition of 64 scans per spot within the range of $4000-500 \mathrm{~cm}^{-1}$ with a resolution of $4 \mathrm{~cm}^{-1}$.

After testing the properties of the first batch of samples (including proportions 1, 2, 3, 4, 11), the results were compared according to the national standard GB/T4897-2015 [24], and densities for which most indicators were eligible were selected to prepare samples for the second time. The other sample of the various proportion were prepared for the second time, and the foaming agent addition amount and PF addition amount were used as the variables to select the

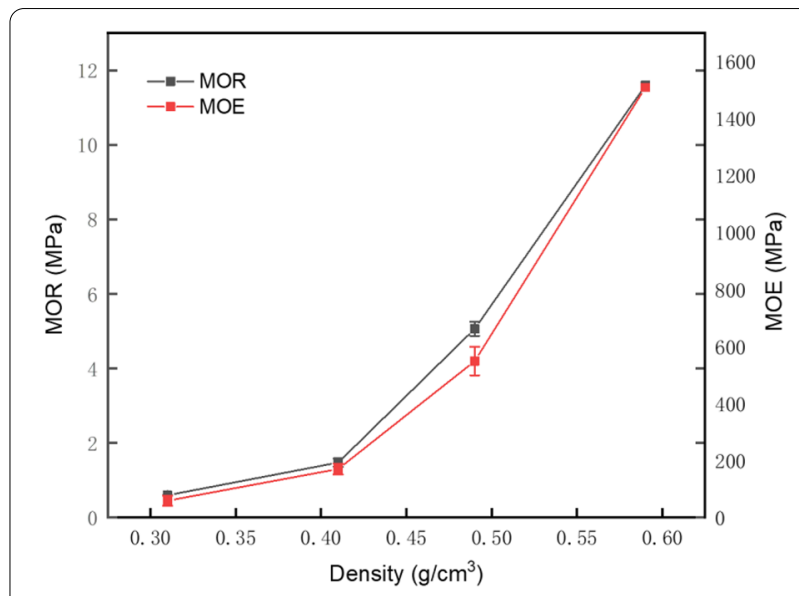

Fig. $2 M O R$ and MOE at different densities

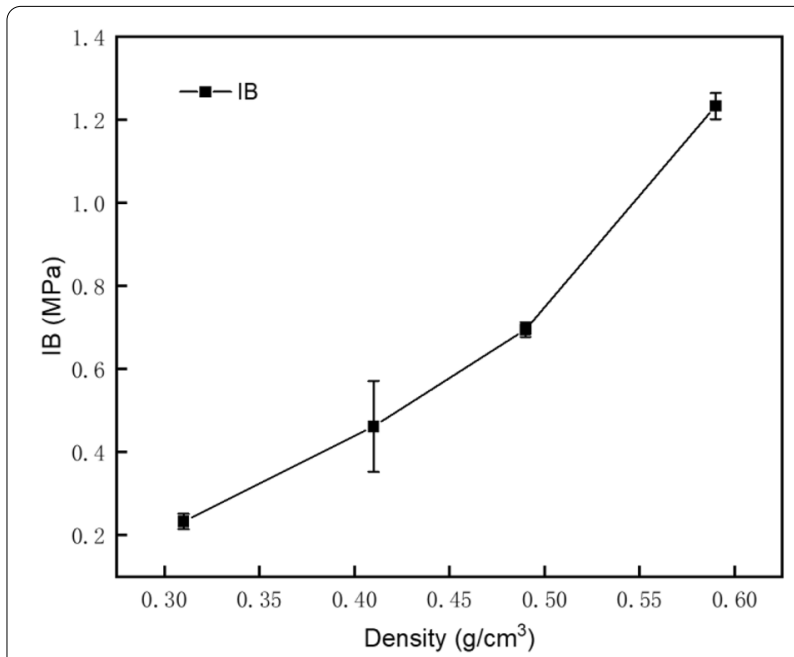

Fig. $3 \mathrm{IB}$ at different densities

proportion which satisfied the lowest index of mechanical strength and physical performance after the test.

\section{Results and discussion Mechanical property analysis}

The three-point bending tests were conducted to select the particleboard with minimum density that satisfied the lowest requirement of the mechanical properties of the national standard. Figures 2 and 3 show the curves of the values of MOR, MOE, and IB for foaming particleboards corresponding to the density of $0.3 \mathrm{~g} / \mathrm{cm}^{3}, 0.4 \mathrm{~g} /$ $\mathrm{cm}^{3}, 0.5 \mathrm{~g} / \mathrm{cm}^{3}, 0.6 \mathrm{~g} / \mathrm{cm}^{3}$, respectively. From the curves, the mechanical parameters, i.e., MOR, MOE and IB, were derived, and the results are summarized in Table 2. Obviously, particleboard with a density of $0.6 \mathrm{~g} / \mathrm{cm}^{3}$ obtained the optimal mechanical properties, and its values are as 
Table 2 Mechanical properties of foaming particleboard with different densities

\begin{tabular}{|c|c|c|c|c|c|c|c|}
\hline Number & $\begin{array}{l}\text { Particleboard design } \\
\text { density }\left(\mathrm{g} / \mathrm{cm}^{3}\right)\end{array}$ & Density $\left(\mathrm{g} / \mathrm{cm}^{3}\right)$ & PF (\%) & $A C(\%)$ & MOR (MPa) & MOE (MPa) & $\mathrm{IB}(\mathrm{Pa})$ \\
\hline 1 & 0.3 & 0.31 & 10 & 1.2 & $0.5905\left(0.0074^{\mathrm{a}}\right)$ & $58.0928(17.2032)$ & $0.2325(0.0186)$ \\
\hline 2 & 0.4 & 0.41 & 10 & 1.2 & $1.4695(0.1141)$ & $169.4461(19.0145)$ & $0.4617(0.1096)$ \\
\hline 3 & 0.5 & 0.49 & 10 & 0 & $5.0619(0.1905)$ & $548.2792(50.0538)$ & $0.6951(0.0175)$ \\
\hline 4 & $0.5 A C$ & 0.53 & 10 & 1.2 & $6.8736(0.8386)$ & $975.4236(82.9129)$ & $0.9325(0.0362)$ \\
\hline 11 & 0.6 & 0.59 & 10 & 1.2 & $11.5915(0)$ & $1509.3648(0)$ & $1.2336(0.0236)$ \\
\hline
\end{tabular}

${ }^{a} \mathrm{ND}$ : the content in brackets is the standard deviation of the results of several repeated experiments

follows: $\mathrm{MOR}=11.5951 \mathrm{MPa}, \mathrm{MOE}=1509.3625 \mathrm{MPa}$, and $\mathrm{IB}=1.2302 \mathrm{MPa}$. It was observed that both bending strength and internal bonding strength exhibited sufficient value when the particleboard were used as ordinary particleboard and furniture-type particleboard under drying status according to the national standard GB/ T4897-2015 [24]. Therefore, the density of $0.6 \mathrm{~g} / \mathrm{cm}^{3}$ was chosen as the requirement for subsequent preparation of particleboard.

As seen from proportion 3 and proportion 4 in Table 2 (the data in parentheses is the standard deviation), the addition of foaming agent changed the micropore structure on the product wood unit and the pore structure of the resin layer, which partially increased the product density, thus strengthening the product mechanical properties (such as MOR, MOE, and IB) and enhancing the product quality.

Huang et al. showed that adding foaming treatment into urea-formaldehyde resin can improve the fluidity of the resin without affecting the solid content and viscosity of the resin [25]. Therefore, the addition of AC foaming agent in this study will help the glue layer to be evenly dispersed in the shavings, which will significantly improve the bonding performance of the board and improve the mechanical properties of the particleboard.

In Figs. 4 and 5, the optimal proportion was determined through changing the PF addition amount at the AC foaming agent content of $1 \%$, after the optimal density was previously determined to be $0.6 \mathrm{~g} /$ $\mathrm{cm}^{3}$. As observed from Figs. 3 and 4, as the PF addition amount increased from 6 to $12 \%$, the MOE, MOR, and IB of foaming particleboard significantly enhanced, and the PF addition amount was positively correlated with its mechanical properties. At the density of $0.6 \mathrm{~g} /$ $\mathrm{cm}^{3}$ and the foaming agent addition amount of $1 \%$, the mechanical properties of particleboard measured at the PF addition amounts of $10 \%$ and $12 \%$ were shown below: $\mathrm{MOE}=1822.6756 \mathrm{MPa}, \mathrm{MOR}=11.041 \mathrm{MPa}$, $\mathrm{IB}=1.0212 \quad \mathrm{MPa}, \quad \mathrm{MOE}=2301.1029 \quad \mathrm{MPa}$, $\mathrm{MOR}=14.6201 \mathrm{MPa}, \mathrm{IB}=1.9763$. In line with the national standard GB/T4897-2015[24], these two

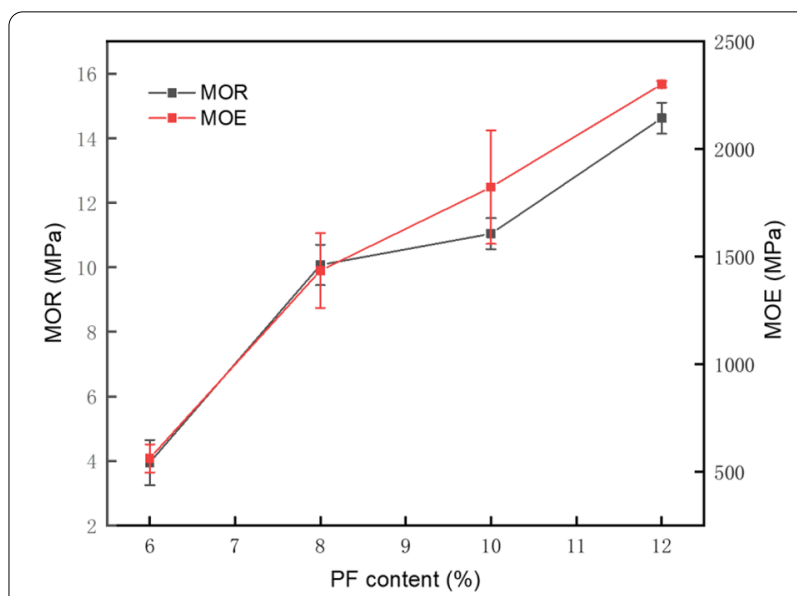

Fig. $4 \mathrm{MOR}$ and $M O E$ at different PF content with $1 \%$ AC foaming agents

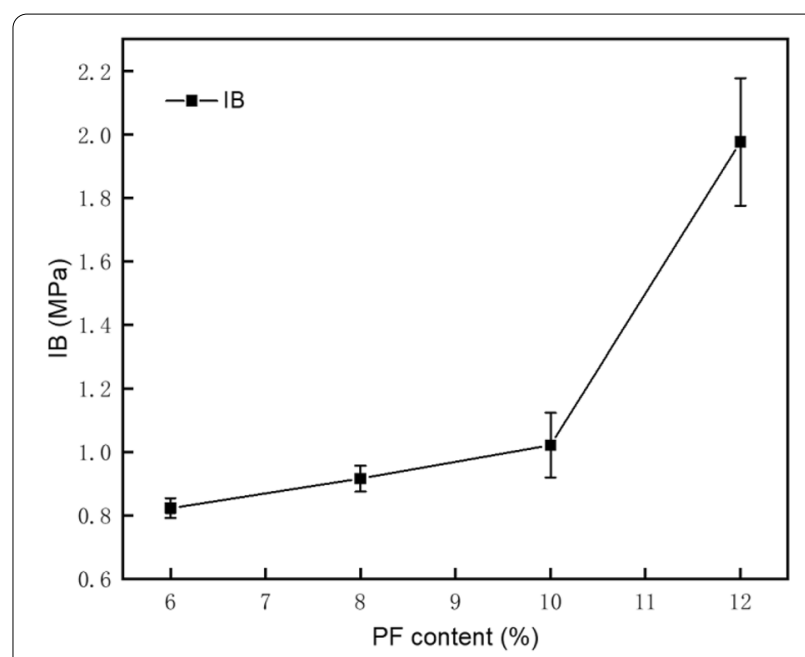

Fig. $5 \mathrm{IB}$ at different PF content with $1 \% \mathrm{AC}$ foaming agents

proportions not only satisfied the mechanical properties of common particleboard at drying status, but also those of furniture-type particleboard at drying status. 


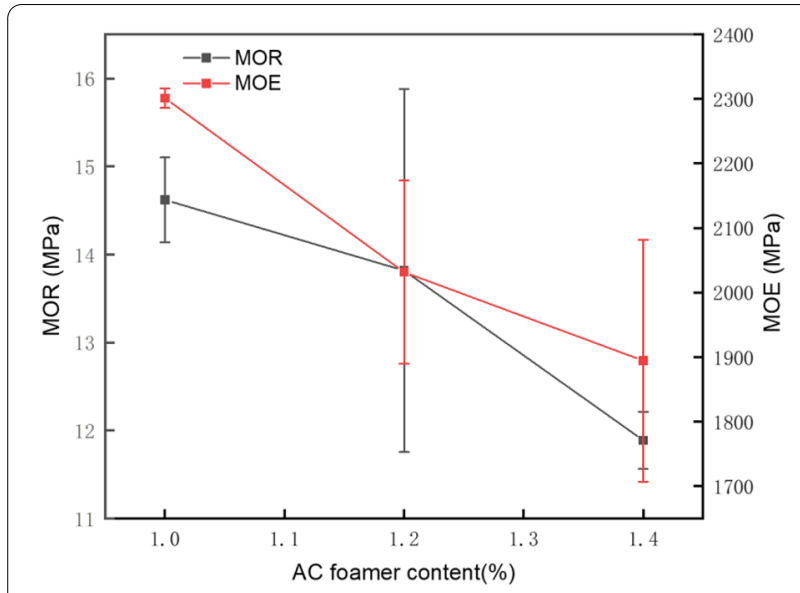

Fig. $6 \mathrm{MOR}$ and MOE at different AC foaming agents with 12\% PF content

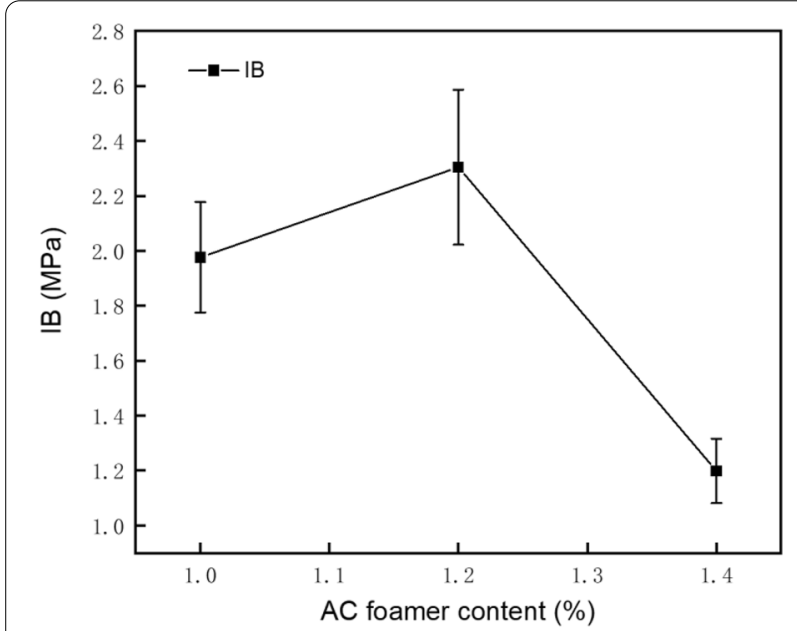

Fig. $7 \mathrm{IB}$ at different $\mathrm{AC}$ foaming agents with $12 \% \mathrm{PF}$ content

In Figs. 6 and 7, after the density was determined to be $0.6 \mathrm{~g} /$ $\mathrm{cm}^{3}$, and the PF addition amount was determined as $12 \%$, the optimal additive amount of AC foaming agent is selected. As seen from Figs. 5 and 6, when the density and adhesive content were determined, MOE and MOR kept declining when the addition amount of foaming agent increased from 1 to $1.4 \%$, while IB showed the first increase and then decrease variation trend, and it peaked when $1.2 \%$ foaming agent was used. Thus, it was clear that MOR and MOE were positively correlated with the foaming agent dosage when the density and adhesive content were determined. The board mechanical properties at the density of $0.6 \mathrm{~g} / \mathrm{cm}^{3}$, PF addition amount of $12 \%$, and AC foaming agent addition amounts of $1 \%, 1.2 \%$ and $1.4 \%$ were as follows, $\mathrm{MOE}=2301.1029 \mathrm{MPa}, \mathrm{MOR}=14.6201 \mathrm{MPa}, \mathrm{IB}=1.9763 \mathrm{MPa}$, $\mathrm{MOE}=2031.7446 \mathrm{MPa}, \mathrm{MOR}=13.8173 \mathrm{MPa}, \mathrm{IB}=2.3043 \mathrm{MPa}$, $\mathrm{MOE}=1894.4115 \mathrm{MPa}, \mathrm{MOR}=11.8874 \mathrm{MPa}, \mathrm{IB}=1.4989 \mathrm{MPa}$. According to the national standard GB/T4897-2015 [24], these three proportions satisfied the mechanical properties of common particleboard at drying status and those of furniture-type particleboard at drying status. Ignoring the economic factor, the optimal proportion of $\mathrm{AC}$ foaming agent of $1 \%$ was selected in this project.

\section{Thickness swelling rate of water absorption of foaming particleboard}

To guarantee that the foaming particleboard prepared in this project satisfied the mechanical properties of common particleboard at drying status, and those of furniture-type particleboard at drying status in the national standard during the actual application, the thickness swelling rate of water absorption of foaming particleboard was tested in test specimens that were previously determined to satisfy the national standard.

As presented in Table 3, among the several proportions that satisfied the national standard mechanical requirements, the minimum $2 \mathrm{~h}$ thickness swelling rate of water absorption was $14.68 \%$. The minimum requirements of particleboard mechanical properties under drying and weight-bearing status are $\mathrm{MOE}=2000 \mathrm{MPa}$, $\mathrm{MOR}=15 \mathrm{MPa}$, and $\mathrm{IB}=0.4 \mathrm{MPa}$, and the $24 \mathrm{~h}$ thickness swelling rate of water absorption is $\leq 19 \%$. In this project, the mechanical properties obtained for proportion 4 were as follows, $\mathrm{MOE}=2301.1029 \mathrm{MPa}, \mathrm{MOR}=14.6201 \mathrm{MPa}$,

Table 3 The mechanical properties meet the thickness swelling rate of water absorption of different proportions under GB/T48972015[24]

\begin{tabular}{|c|c|c|c|c|c|c|}
\hline Number & $\begin{array}{l}\text { Particleboard design } \\
\text { density }\left(\mathrm{g} / \mathrm{cm}^{3}\right)\end{array}$ & Density $\left(\mathrm{g} / \mathrm{cm}^{3}\right)$ & PF (\%) & $A C(\%)$ & $\begin{array}{l}\text { TS rate of water } \\
\text { absorption }(2 \mathrm{~h})(\%)\end{array}$ & $\begin{array}{l}\text { TS rate of water } \\
\text { absorption }(24 \mathrm{~h}) \\
\text { (\%) }\end{array}$ \\
\hline 3 & 0.6 & 0.63 & 10 & 1 & 17.59 & 18.35 \\
\hline 4 & 0.6 & 0.57 & 12 & 1 & 14.68 & 16.82 \\
\hline 8 & 0.6 & 0.61 & 12 & 1.2 & 15.57 & 19.83 \\
\hline 11 & 0.6 & 0.59 & 10 & 1.4 & 17.27 & 18.18 \\
\hline 12 & 0.6 & 0.61 & 12 & 1.4 & 15.74 & 18.35 \\
\hline
\end{tabular}


$\mathrm{IB}=1.9763 \mathrm{MPa}$, and the $24 \mathrm{~h}$ thickness swelling rate of water absorption was $16.82 \%$. Obviously, all properties satisfied the national standard requirements, except for the slightly poor MOR. As a result, the optimal proportion obtained from the tests was proportion 4 (board density of $0.6 \mathrm{~g} / \mathrm{cm}^{3}$, PF addition amount of $12 \%$, and $\mathrm{AC}$ foaming agent addition amount of $1 \%$ ). It was clearly observed from Fig. 8 that, when the density was $0.5 \mathrm{~g} /$ $\mathrm{cm}^{3}$ and the adhesive content was $10 \%$, the set of samples with the addition of foaming agent had substantially lower thickness swelling rate of water absorption than samples with no addition of foaming agent, either for $2 \mathrm{~h}$ or $24 \mathrm{~h}$. This result suggested that the foaming agent was able to enhance product dimensional stability and reduce the thickness swelling rate of water absorption. It is speculated that this phenomenon may be caused by the surface tension of the tiny pores generated by the foaming agent on the particle unit.

\section{Heat conductivity of foaming particleboard}

Heat conductivity, one of important indexes tested in this project reflects the heat transferability of the product under steady-state heat transfer. A product with a lower heat conductivity is more suitable as the heat-insulating material. The table below shows the influences of variables on the heat conductivity at different proportions.

It was observed from Table 4 that, the foaming particleboard density, foaming agent addition amount, and PF addition amount did not influence its heat conductivity. However, from the opposite perspective, the experiments in this project also verified that the contents of adhesive and other trace additives in particleboard did not exert any significant impact on its heat insulation property.
Besides, change in the particleboard density at $\leq 0.6 \mathrm{~g} /$ $\mathrm{cm}^{3}$ had no significant effect on the material heat insulation property as well. Additionally, this experiment also verified that the heat conductivity of particleboard at the density of $\leq 0.6 \mathrm{~g} / \mathrm{cm}^{3}$ was $0.03 \mathrm{~W} /(\mathrm{m} \mathrm{k})$. According to the national standard, materials with a heat conductivity of less than $0.05 \mathrm{~W} /(\mathrm{m} \mathrm{k})$ are referred to as efficient heat insulation materials. Therefore, it was concluded that the foaming particleboard prepared in this experiment had favorable heat insulation property, which might serve as the efficient heat insulation material.

\section{Characterization of the microstructure and morphology of foaming particleboard}

The mechanical experimental and physical test demonstrated that the particleboard with foaming agent exhibited superior mechanical and physical performance over the control. Therefore, to interpret this phenomenon, the particle surfaces morphology was observed using SEM, as shown in Fig. 9. Figure 9a, b are photographs of particleboard with proportion 4 , which are not significantly different from ordinary particleboard. For particles of the proportion 4, a homogeneous surface, including evenly distributed pits, was clearly observed in Fig. 9c. The arrangement spacing between the pores is about 3-4 times the pore size, the pore size is about $3-4 \mu \mathrm{m}$, and the number of holes each $\mu \mathrm{m}^{2}$ is about 0.010. And it is the only pore structure that can be seen under the SEM. In contrast to the particles of the proportion 4, the particles of the proportion 3 with foaming agents exhibited continuous and homogeneous pore structure (Fig. 9d). The pore structure that clearly different from of wood pits on the particle surface is displayed as the larger pore
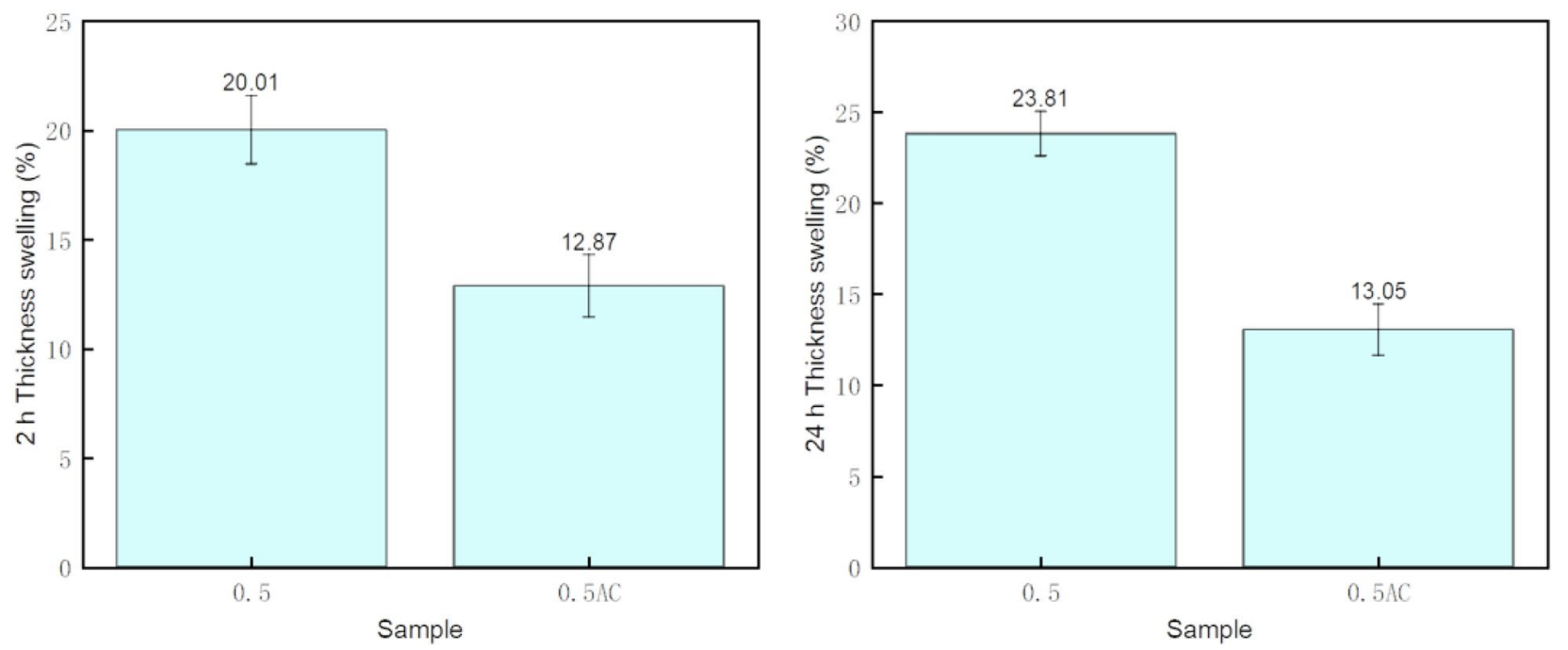

Fig. 8 The thickness swelling rate of water absorption of samples with foaming agent and the control group with density $0.5 \mathrm{~g} / \mathrm{cm}^{3}$ 
Table 4 Heat conductivity of particleboard in different proportions

\begin{tabular}{|c|c|c|c|c|c|}
\hline Number & $\begin{array}{l}\text { Particleboard design density } \\
\left(\mathrm{g} / \mathrm{cm}^{3}\right)\end{array}$ & Density $\left(\mathrm{g} / \mathrm{cm}^{3}\right)$ & PF (\%) & $A C(\%)$ & $\begin{array}{l}\text { Heat } \\
\text { conductivity } \\
(W /(m \cdot k))\end{array}$ \\
\hline 1 & 0.6 & 0.6 & 6 & 1 & 0.029 \\
\hline 2 & 0.6 & 0.62 & 8 & 1 & 0.029 \\
\hline 3 & 0.6 & 0.63 & 10 & 1 & 0.029 \\
\hline 4 & 0.6 & 0.57 & 12 & 1 & 0.029 \\
\hline 5 & 0.6 & 0.61 & 6 & 1.2 & 0.029 \\
\hline 6 & 0.6 & 0.58 & 8 & 1.2 & 0.029 \\
\hline 7 & 0.6 & 0.59 & 10 & 1.2 & 0.029 \\
\hline 8 & 0.6 & 0.61 & 12 & 1.2 & 0.029 \\
\hline 9 & 0.6 & 0.62 & 6 & 1.4 & 0.029 \\
\hline 10 & 0.6 & 0.58 & 8 & 1.4 & 0.029 \\
\hline 11 & 0.6 & 0.59 & 10 & 1.4 & 0.029 \\
\hline 12 & 0.6 & 0.61 & 12 & 1.4 & 0.029 \\
\hline 13 & 0.3 & 0.31 & 10 & 1.2 & 0.029 \\
\hline 14 & 0.4 & 0.41 & 10 & 1.2 & 0.029 \\
\hline 15 & 0.5 & 0.49 & 10 & 0 & 0.029 \\
\hline 16 & $0.5 \mathrm{AC}$ & 0.53 & 10 & 1.2 & 0.029 \\
\hline 17 & 0.6 & 0.59 & 10 & 1.2 & 0.029 \\
\hline
\end{tabular}

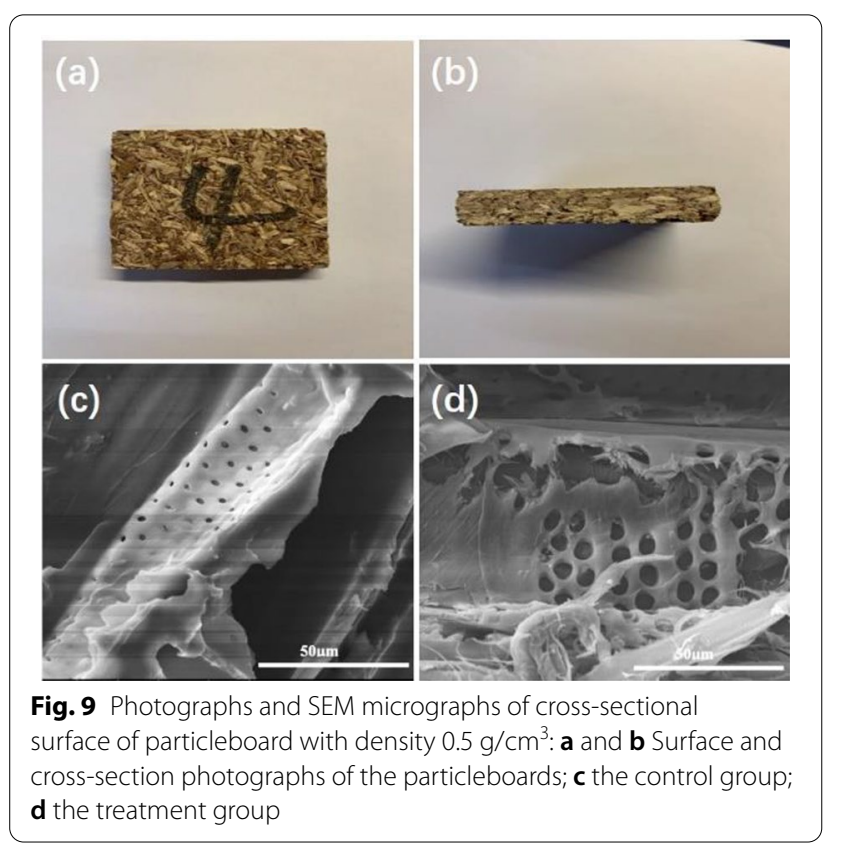

size of about 7-8 $\mu \mathrm{m}$, which is about $0.5-1$ time the pore size, so it strongly demonstrated that the foaming agents were well destroying the wood cell structure and creating pores effectively.

Figure 10 shows the cross-section microstructures of three different samples at the same density of $0.6 \mathrm{~g} /$ $\mathrm{cm}^{3}, \mathrm{PF}$ resin addition amount of $12 \%$, and different
AC foaming addition amounts $(1.4 \%, 1.2 \%$, and $1.0 \%)$ under the same hot pressing processes as those before (a hot pressing temperature at $180{ }^{\circ} \mathrm{C}$, a hot pressing gauge pressure at $4 \mathrm{MPa}$, and hot pressing time of $10 \mathrm{~min}$ ). As clearly observed from the images of three different foaming agent addition amounts, the incorporation of $\mathrm{AC}$ foaming agent from 1 to $1.4 \mathrm{wt} \%$ generated distinctive fracture morphology. The sample with the foaming agent addition amount of $1.4 \%$ possess the finest pore size, about $3.44 \mu \mathrm{m}$, and the number of pores per unit area $\left(1 \mu \mathrm{m}^{2}\right)$ is about 0.015 . For the sample with the foaming agent addition amount of $1.2 \%$, there was moderate foaming pore number that is about $0.013 / \mu \mathrm{m}^{2}$ and the pore size $3.75 \mu \mathrm{m}$, while the foaming pore number per unit area and the pore size in the sample with $1.0 \%$ foaming agent content is $0.010 / \mu \mathrm{m}^{2}$ and $4.14 \mu \mathrm{m}$, respectively. The pore structure characteristics of all the above samples are shown in Table 5. It confirmed that the AC foaming agent generated foaming pores on the surface of the cell wall of particles successfully under high temperature. The content of foaming agent in samples played a critical role in the procedure of the foaming pores formation, as the decomposition of the foaming agent at high temperature is an exothermic reaction, which caused the emerging of vast hotspot, then the high temperature reduces the surface tension of the material, making it convenient for the $\mathrm{N}_{2}$ expanding and forming pores [26]. 

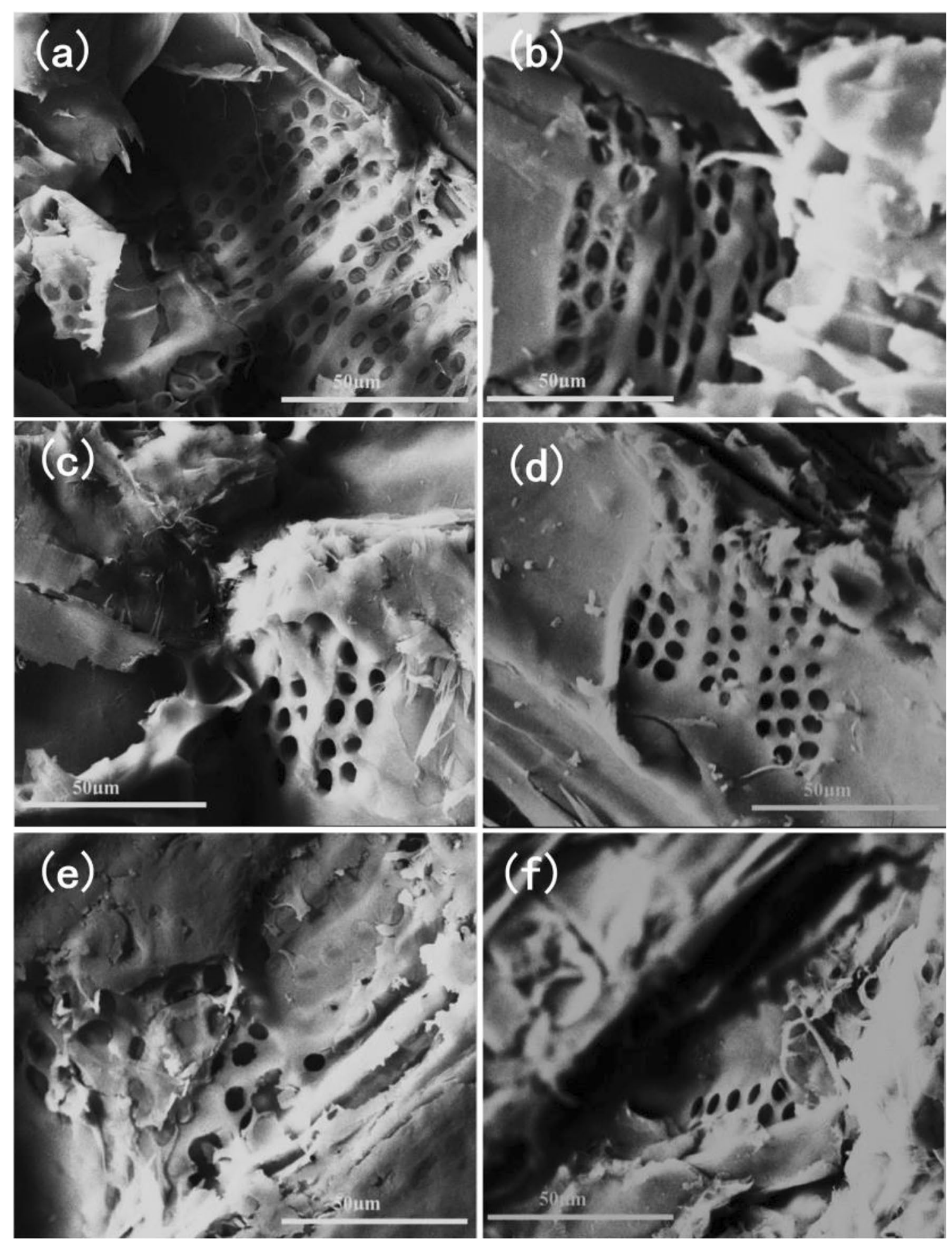

Fig. 10 SEM micrographs of cross-sectional surface of particleboard with density $0.6 \mathrm{~g} / \mathrm{cm}^{3}$ : $\mathbf{a}$, b particleboard with $1.4 \%$ foaming agent, $\mathbf{c}$, d particleboard with $1.2 \%$ foaming agent, $\mathbf{e}$, $\mathbf{f}$ particleboard with $1.0 \%$ foaming agent 
Table 5 Characteristics of surface pore of particles with different AC foaming agent content

\begin{tabular}{lll}
\hline $\begin{array}{l}\text { Mass fraction of AC foaming } \\
\text { agent }(\%)\end{array}$ & Pore numbers $\left(\mu \mathrm{m}^{2}\right)$ & $\begin{array}{l}\text { Average } \\
\text { pore size } \\
(\mu \mathrm{m})\end{array}$ \\
\hline 1.0 & 0.010 & 4.14 \\
1.2 & 0.013 & 3.75 \\
1.4 & 0.015 & 3.44 \\
\hline
\end{tabular}

The sample with the foaming agent addition amount of $1.4 \%$ had the greatest foaming pore number per unit area, with moderate pore diameter homogeneity. For the sample with the foaming agent addition amount of $1.2 \%$, there was moderate foaming pore number per unit area, with moderate pore diameter homogeneity, while the foaming pore number per unit area in the sample with $1.0 \%$ foaming agent content was less, with moderate pore diameter homogeneity.

It was observed from the physical and mechanical property conclusions that, the product mechanical properties gradually declined as the increase in foaming agent addition amount. Thus, it was speculated that the foaming pore number and pore diameter greatly affected the material physical and mechanical properties, and excessive foaming pores partially declined the mechanical properties. Meanwhile, the comparison between samples with foaming agent addition and control groups showed that the addition of foaming agents indeed contributed to improving the product's physical and mechanical properties. Different foaming agents have different effects, thus affecting the surface quality [27]. The surface quality of polymer micro-foamed composite materials, such as surface roughness, surface flatness, etc., will have different effects due to the different types of foaming agents used, but the foaming agent in this program does not affect the surface quality of the particleboard.

\section{FTIR analysis}

FTIR spectrums of particleboard sample with various proportions, $\mathrm{AC}$ foaming agent, and $\mathrm{PF}$ resin were obtained by using the infrared spectrophotometer, and transmittance graphs are shown in Fig. 11. In the spectrum of AC foaming agent, the peaks at $3328(\mathrm{~N}-\mathrm{H}$ stretch), $1727(\mathrm{C}=\mathrm{O}$ stretch), $1631(\mathrm{~N}-\mathrm{H}$ bend $)$, and $1454 \mathrm{~cm}^{-1}(\mathrm{~N}=\mathrm{N}$ stretch) were the typical bands of $\mathrm{AC}$ foaming agent molecules. In the spectrum of PF, the characteristic peaks at $3417\left(\mathrm{O}-\mathrm{H}\right.$ stretch) and $1606 \mathrm{~cm}^{-1}$ $(\mathrm{C}-\mathrm{H}$ stretch) were the typical bands of PF resin. Compared with the spectrum of $\mathrm{AC}$ foaming agent and $\mathrm{PF}$ resin, the spectrum of PB1.0, PB1.2 and PB1.4 showed new peaks at 1054, 1056, and $1033 \mathrm{~cm}^{-1}$. The existence of these peaks that indicating tensile strength of $\mathrm{C}-\mathrm{O}$ band

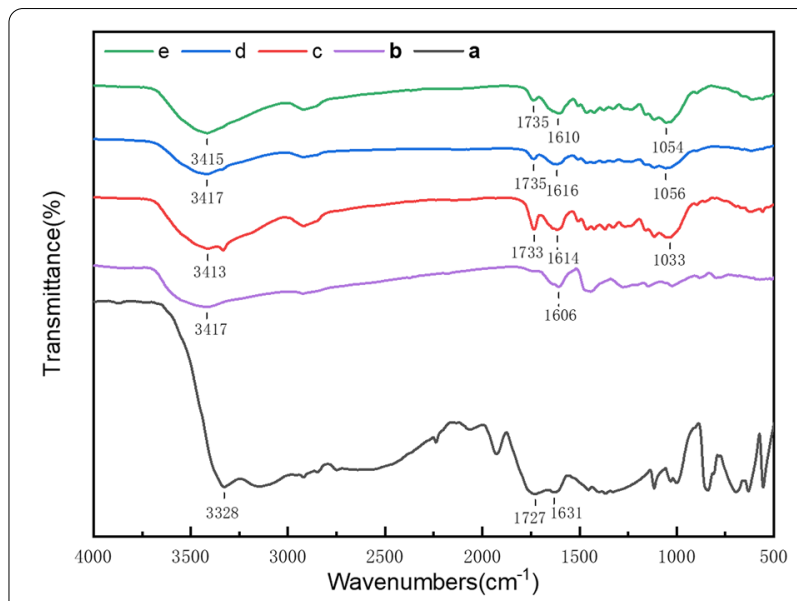

Fig. 11 Fourier transform infrared (FTIR) spectra of raw materials and particleboard powder: a AC foaming agent; b PF resin; $\mathbf{c}$ particleboard with $1.0 \%$ AC foaming agent; $\mathbf{d}$ particleboard with $1.2 \%$ AC foaming agent; e particleboard with $1.4 \%$ AC foaming agent

is determined by the presence of hydroxyl groups on the cellulose molecules. And the characteristic peak corresponding to the $\mathrm{C}=\mathrm{O}$ stretching vibrations of Azodicarbonamide also shifted from 1727 to 1733 or $1735 \mathrm{~cm}^{-1}$ as the thermal degradation of AC in the composite. In addition, all composites demonstrate peaks at 1610, 1616 and $1610 \mathrm{~cm}^{-1}$, which correspond to the aromatic ring vibrations in the PF resin. It is speculated that the absence of obvious characteristic peak of $\mathrm{N}=\mathrm{N}$ in the composite this may be caused by the radically thermal degradation of the AC foaming agent. The result confirmed that the foaming agent successfully produced pores, which is consistent with the results of our previous discussion.

\section{Conclusions}

In this paper, the effect of $\mathrm{AC}$ foaming agent on the mechanical, physical and chemical properties of foaming particleboards was studied. The conclusions are as follows:

1. The experiment in this work verifies that, compared with the particleboard without an addition of foaming agent, the foaming particleboard adding $\mathrm{AC}$ foaming agent has partially elevated mechanical properties, and the thickness swelling rate of water absorption significantly reduces.

2. Generally, the particleboard prepared with the density of $0.6 \mathrm{~g} / \mathrm{cm}^{3}$, the PF resin addition amount of $12 \%$, and the AC foaming agent addition amount of $1 \%$ obtained the best physical and mechanical properties including MOE, MOR, IB, and the $24 \mathrm{~h}$ thickness swelling that corresponding to $2301.1029 \mathrm{MPa}$, 14.6201 MPa, 1.9763 MPa, and 16.82\%, respectively. 
3. The addition of diluted $\mathrm{AC}$ foaming agent into Populus wood particles when blending the adhesive results in the occurrence of foaming micropores on the interior duct surface of Populus wood particles, which positively affects the overall product performance after sizing and hot pressing, enhances the physical and mechanical properties, and improves the product quality without greatly affecting the production cost.

4. Finally, characterization by SEM indicated that the thermal degradation of the foaming agent successfully produced micro-foaming pores on the surface of the particles.

\begin{abstract}
Abbreviations
AC: Azodicarbonamide; PF: Phenol formaldehyde; FTIR: Fourier transform infrared spectroscopy; PB: Particleboard; EPS: Expanded polystyrene; PVC: Polyvinyl chloride plastics; PE: Polyethylene; HDPE: High-density polyethylene; AA: Acetic acid; MOR: Modulus of rupture; MOE: Modulus of elasticity; IB: Internal bonding strength; SEM: Scanning electron microscope; PB1.0: Particleboard with 1\% AC foaming agents; PB1.2: Particleboard with 1.2\% AC foaming agents; PB1.4: Particleboard with 1.4\% AC foaming agents.
\end{abstract}

\section{Acknowledgements}

The authors acknowledge the support of the Advanced Analysis and Testing Center of Nanjing Forestry University.

\section{Authors' contributions}

$\mathrm{RH}$ designed the study and conducted parts of experiments and data analysis. $\mathrm{XB}$ wrote the initial manuscript. XB performed the composite property testing/data analysis. Both authors read and approved the manuscript.

\section{Funding}

This collaborative study was supported by Major projects of Natural Science Foundation of Jiangsu (18KJA220002); China Postdoctoral Science Foundation: Special Program (2017T100313); China Postdoctoral Science Foundation: General Program (2016M601821); Teaching instrument project of Nanjing Forestry University (nlzzyq202113).

\section{Declarations}

\section{Competing interests}

The authors declare that they have no competing interests.

Received: 16 April 2021 Accepted: 28 July 2021

Published online: 04 August 2021

\section{References}

1. Hua J, Lu RS, Pu AB, Ling N (2000) Study on processing technology of wheat straw particleboard preparing section. China For Prod Ind 27:20-22

2. Allen (2005) Overview of domestic research on light particleboard. For Mach Woodwork Equip 12:4-6

3. JIS A 5908-2003 (2003) Particleboard. Japanese Standards Association, Tokyo (in Japanese)

4. Wang MG, Shi SJ, Liu C, Gao Y (1995) Development and study of lightweight particleboard. China For Prod Ind 22:3-5
5. Wong ED, Zhang M, Han G, Kawai S, Wang Q (2000) Formation of the density profile and its effects on the properties of fiberboard. J Wood Sci 46:202-209

6. Xu AY, Sugawara R, Widyorini R, Han GP, Kawai S (2004) Manufacture and properties of low-density binderless particleboard from kenaf core. J Wood Sci 50:62-67

7. Shalbafan A, Luedtke J, Welling J, Fruehwald A (2013) Physiomechanical properties of ultra-lightweight foam core particleboard: different core densities. Holzforschung 67:169-175

8. Wang DH, Sun XZS (2002) Low density particleboard from wheat straw and corn pith. Ind Crops Prod 15:43-50

9. Zeng QZ, Rao JP, Wu CC, Xiong DX, Huang ZY (2000) Study on manufacturing thick lightweight particleboard with Chinese fir thinning timber. Wood Ind 14:3-6

10. Wu LN (2000) Development of fire resistant oriented structure particleboard for Chinese fir thinning timber. Build Wood Based Panels 04:23-24

11. Hu YH (1999) Application of Artificial fast-growing Chinese fir thinning wood in oriented strand structure particleboard. Wood Process Mach 4:18-19

12. Yu YM (2006) Study on low density Cement-bond Particleboard. Dissertation, Nanjing Forestry University

13. Zhao CH, Hong ZL, Wang XP (1995) Preliminary study on phenolic light particleboard. China For Prod Ind 06:7-9

14. Jiang WJ, Wang AR, Lan P, Lu ZZ, Guo R, Gao ZH (2016) Development of single board composite particle/foamed polystyrene wood composite board. Wood Ind 30:18-21

15. Zhang Y, Hua YK (2001) Study on manufacturing technology of wood fiber and wheat straw particleboard. Wood Ind 05:6-9

16. Han Z (2010) Study on PVC-based wood plastic composite foam flooring substrate. Dissertation, Northeast Forestry University

17. Wang Y (2014) Study on properties of PVC based wood plastic composites. Dissertation, Hebei University of Technology

18. Xu B (2017) Study on modified straw fiber/PVC wood plastic composites. Dissertation, Jinan University

19. Chen WB (2013) Study on toughening and foaming process of PE-based wood-plastic composites. Dissertation, Shanxi University of Science and Technology

20. Wang LL (2015) Preparation and properties of HDPE / rice husk foamed wood plastic composites. Dissertation, Nanjing Agricultural University

21. Nadhari W, Danish M, Nasir M, Geng BJ (2019) Mechanical properties and dimensional stability of particleboard fabricated from steam pre-treated banana trunk waste particles. J Build Eng. https://doi.org/10.1016/j.jobe. 2019.100848

22. Iswanto A, Febrianto F, Hadi Y, Ruhendi S, Hermawan D, Fatriasari W (2018) Effect of particle pre-treatment on properties of Jatropha fruit hulls particleboard. J Korean Wood Sci Technol 46:155-165

23. Widyorini R, Umemura K, Kusunaningtyas A, Prayitno T (2017) Effect of Starch Addition on Properties of Citric Acid-bonded Particleboard Made from Bamboo. BioResources 12:8068-8077

24. GB/T4897-2015 (2015) Particleboard. General Administration of Quality Supervision, National Standardization, Administration of China, Beijing

25. Huang TH, Wang JF, Song LH, Lei FJ, Luan J (2021) The effect of Azodicarbonamide blowing agent on the properties of urea-formaldehyde resin. China For Prod Ind 58:12-15

26. Zhou YH, He L, Gong W (2018) Effects of zinc acetate and cucurbit 6 uril on PP composites: crystallization behavior, foaming performance and mechanical properties. E-Polymers 18:491-499

27. Gong W, He L, Ban DM, Fu H, Yin XG (2019) Effect of Different Foaming Agents on Foaming and Surface Quality of Microcellular PP Composites. J Guizhou Normal Univ (Nat Sci Ed) 37:15-19

\section{Publisher's Note}

Springer Nature remains neutral with regard to jurisdictional claims in published maps and institutional affiliations. 